\title{
The qua-Problem, Meaning Scepticism, and the Life-World
}

- Anar Jafarov

\begin{abstract}
Michael Devitt and Kim Sterelny (Language and reality: An introduction to the philosophy of language. MIT Press, Cambridge, 1999) argue that the pure causal theory of reference faces a problem, which they call the qua-problem. They propose to invoke intentional states to cope with it. Martin Kusch (A sceptical guide to meaning and rules. Acumen, Chesham, 2006), however, argues that, because Devitt and Stereleny invoke intentional states to solve the problem, their causal-hybrid theory of reference is susceptible to Kripke's sceptical attack. Kusch thinks that intentional states are what allows the sceptic to get a foothold and thus interpret words in a weird way. In his view, Kripke is therefore correct in not regarding a causal theory as a solution to the problem. I think, however, that there is room to defend a causal-hybrid theory of reference. Drawing on Husserl's notion of the life-world, I argue that this notion is helpful for overcoming some aspects of the qua-problem and the meaning scepticism which Devitt and Sterelny's causal-hybrid theory of reference faces.
\end{abstract}

